\title{
A percepção e cognição climática dos agricultores e pesquisadores como subsídio ao cultivo de roseiras no rio grande do sul
}

\author{
The perception and cognition of climate of agriculturists and researchers as subsidy to the cultivation of roses \\ Cássio Arthur Wollmann', Emerson Galvani² \\ ' Departamento de Geociências - Universidade Federal de Santa Maria \\ 2 Departamento de Geografia - Universidade de São Paulo.
}

\section{RESUMO}

O Estado do Rio Grande do Sul destaca-se, há décadas, no cenário agropecuário nacional e até mesmo internacional, pela sua alta capacidade e diversidade de produção agropecuária, dentre as quais, a floricultura, sendo a rosa, a principal flor cultivada e comercializada nos cenários estadual e nacional. Nesse sentido, sendo o clima um dos principais condicionantes ao seu cultivo, esta pesquisa procurou investigar a percepção climática dos roseiristas, analisando se as condições climáticas do Rio Grande do Sul têm sido ou não favoráveis ao cultivo de roseiras. Também foram entrevistados técnicos com a finalidade de cruzamento dos dados científicos com os empíricos coletados junto aos agricultores. Realizaram-se trabalhos de campo com aplicação de questionários, e evidenciou-se o grande conhecimento tanto por parte dos técnicos quanto dos agricultores. O que chama a atenção é que foi perguntado aos dois grupos de entrevistados as mesmas questões, mas de forma diferente, respeitando-se seu vocabulário, obtendo-se, ao final, semelhantes respostas, tanto em relação à análise da planta quanto sobre o clima do Rio Grande do Sul. De uma forma geral, segundo a visão empírica dos agricultores, o clima do Rio Grande do Sul, bem como de sua região de produção, pode ser enquadrado entre condições regulares a boas para o cultivo da roseira.

Palavras-chave: Percepção climática, roseiricultores, condições climáticas, Rio Grande do Sul.

\begin{abstract}
The State of Rio Grande do Sul stands out, for decades, the national agricultural scenario, and even internationally for its high capacity and diversity of agricultural production, among them, could not fail to highlight the flowers, the rose being the main flower grown and marketed in the state and national scenarios. In this sense, the climate being one of the main constraints to its cultivation, this study concerns to investigate the perception of climate farmer roses, analyzing if the climatic conditions of Rio Grande do Sul have been favorable or unfavorable to the cultivation of roses. Were also interviewed technical people, whose purpose of crossing with the empirical scientific data collected from the farmers. Were carried out fieldwork with questionnaires, and demonstrated the great knowledge by both technicians and farmers. What is striking is that both groups were asked the same questions of respondents, but in a different way, respecting your vocabulary, getting in the end, similar responses, both in relation to the analysis of the plant and on the climate of Rio Grande do Sul. Overall, according to the empirical view of farmers, the climate of Rio Grande do Sul, as well as its region of production, can be framed from regular to good conditions for the cultivation of roses.
\end{abstract}

Keywords: Climate perception, farmer roses, climate conditions, Rio Grande do Sul. 


\section{INTRODUÇÃO}

O Estado do Rio Grande do Sul destaca-se, há décadas, no cenário agropecuário nacional, e até mesmo internacional, pela sua alta capacidade e diversidade de produção agropecuária, dentre as quais, não poderia deixar de se destacar a floricultura.

No Rio Grande do Sul, a roseira foi introduzida com a vinda dos imigrantes alemães na primeira metade do século XIX, adaptando-se às condições climáticas do Estado. Porém, seu cultivo com finalidade comercial iniciou-se em meados da década de 1970, segundo dados da Associação Rio-Grandense de Floricultura (AFLORI), também nas áreas de colonização alemã (Vales dos rios Caí e Taquari), baseando-se, especialmente, nos cultivos de rosáceas, cravos/cravíneas e crisântemos, tendo aquela, a maior parcela do total produzido e comercializado (KÄMPF, 1999; PETRY, 2000).

O crescimento observado na produção de flores, especialmente das rosáceas, deve-se quase que exclusivamente a sua beleza, levando à população a consumir mais esta variedade em comparação às demais, fato também, associado ao seu preço, que não está entre os mais elevados do mercado de flores. Entretanto, ressalta-se que o cultivo de roseiras não é uma prática agrícola de fácil manejo, pois o trabalho é eminentemente manual, e deve ser feito com todo cuidado, dada à fragilidade das flores.

Do ponto de vista comercial, todas as roseiras, dos mais de 200 gêneros existentes, são aproveitadas e podem ser cultivadas de três formas diferentes: as arbustivas, as cercas-vivas e as rasteiras. Esta última é a mais comum de ser comercializada não só no Brasil ou no Rio Grande do Sul, mas mundialmente, pois floresce o ano inteiro.

No Brasil, é produzida em quase todo território nacional, especialmente nos estados de São Paulo, Rio de Janeiro, Minas Gerais, Santa Catarina, Paraná, Rio Grande do Sul, Bahia, Alagoas, Pernambuco e Ceará.

A maior parte do cultivo de roseiras no Rio Grande do Sul ocorre em pequenas propriedades (de 1 a 10 hectares) cuja mão-de-obra é predominantemente familiar. Desse total, a maioria dos roseirais é cultivada ao ar livre (em torno de $85 \%$ ). Essa produção, portanto, volta-se essencialmente para o abastecimento do mercado florista gaúcho, pois foi apenas no final da década de 1990 que as roseiras produzidas no Estado começaram a concorrer no mercado nacional e internacional (KÄMPF; DAUDT, 1999).

Segundo Wollmann e Galvani (2012), para que as rosáceas tenham um desenvolvimento pleno, a temperatura deve variar entre $12^{\circ} \mathrm{C}$ e $18^{\circ} \mathrm{C}$, a umidade relativa do ar aconselhável deve ser abaixo de $70 \%$, a precipitação deve cair de forma a não prejudicar o roseiral, ou seja, sem grandes temporais, a insolação diária deve ficar entre 6 e 7 horas, bem como as rajadas de vento devem ser evitadas, pois podem levar à queda das pétalas. Assim, as áreas compreendidas pelo Planalto da Bacia do Paraná (setor norte e noroeste do Estado do Rio Grande do Sul), são consideradas as áreas mais favoráveis ao cultivo da rosa, sendo o inverno, o Estado totalmente inapto para seu cultivo.

\section{OBJETIVO DA PESQUISA}

Pretendeu-se investigar a percepção climática dos floricultores, especialmente os roseiristas, se as condições climáticas do Rio Grande do Sul têm sido ou não favoráveis ao cultivo de roseiras. As mesmas questões também foram feitas a pesquisadores da floricultura ornamental no Estado, obviamente, respeitando-se a linguagem técnica.

\section{MATERIAIS E MÉTODOS}

As formas de investigação do conhecimento das pessoas, seja este conhecimento empírico ou cientifico, mas que tenham vivenciado determinados fenômenos naturais, não é tarefa fácil, pois encontrar pesquisas que podem ser aplicados à realidade pessoal de cada área de estudo e objetivos de trabalho é difícil, dado ao pequeno número de pesquisas voltadas para este objetivo.

Conforme aborda Oliveira; Del Rio (1996, p. 10), atribuir caráter científico a um estudo calcado na fenomenologia requer que sejam:

Os resultados expressos das percepções, dos processos cognitivos, julgamentos e expectativas da cada indivíduo... que, embora também admita correlações, é incomensurável e, portanto, impossível de se verificar pelas relações diretas de causa-efeito e de ser compreendida em sua plenitude.

Nesse sentido, ao saber que os trabalhos de percepção ambiental e climática para o Rio Grande do Sul restringem-se aos de Sartori (2000; 2002; 2003a; 2003b; 2005), e que a referida autora 


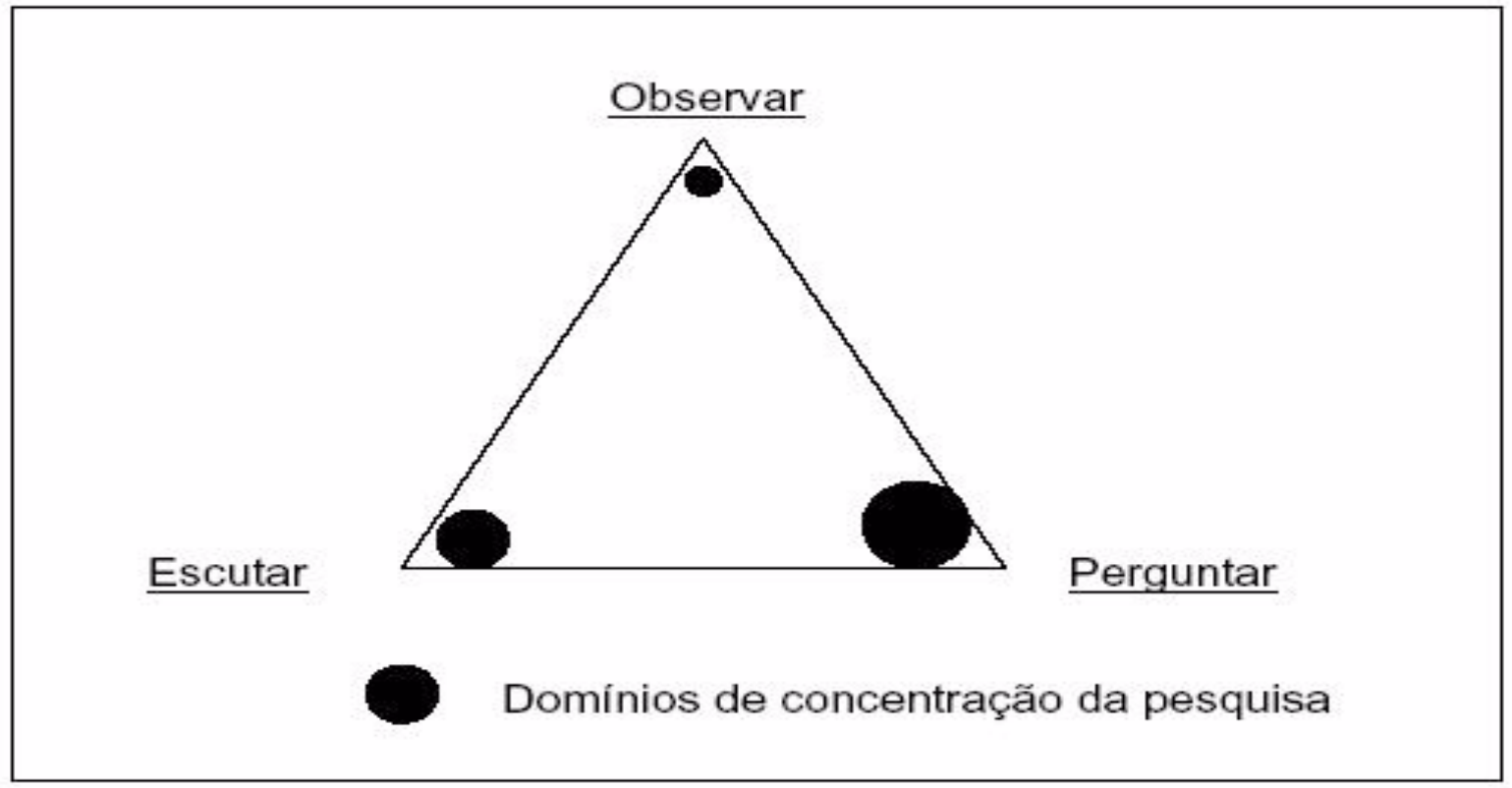

Figura 01 - Triângulo Metodológico de Whyte. Fonte: WHYTE, A. (1978, p. 21) Org.: WOLLMANN, C. A., 2011.

baseou-se em Whyte (1978) para investigar e avaliar qualitativa e quantitativamente a percepção climática da população da região central do Estado. Segundo Sartori (2005, p. 1):

A percepção ambiental do homem rural resulta da perspicácia, inteligência, atenção, vivência/ experiência e sensibilidade individual frente aos acontecimentos do seu entorno natural; [e] por necessidade prática, a observação da natureza no seu trabalho...

Para a formulação do questionário de entrevista aos agricultores e aos pesquisadores, baseou-se a construção no triângulo metodológico de Whyte (op. cit., p.21), conforme mostra a Figura 01.

Para Whyte (op. cit.), certas técnicas de pesquisa manifestam o complexo mundo que é o das ciências interdisciplinares. Neste contexto, é que se insere a percepção ambiental como uma das tendências de pesquisa da Geografia, e também da Climatologia Geográfica, como aprofundado em Sartori (2000).

Assim, investigar a percepção, tanto dos agricultores quanto dos pesquisadores, se o clima do Rio Grande do Sul tem sido ou não favorável ao plantio de roseiras, torna-se necessário o uso do triângulo metodológico que serviu principalmente para a construção do questionário (instrumento de pesquisa) de entrevistas formulado para estes dois grupos de pessoas.

O triângulo consiste em três métodos de pesquisa em percepção do meio ambiente: o per- guntando, o ouvindo e o registrando e o observando. O primeiro consiste em aplicação de formulários de perguntas para ser usado em entrevistas; o segundo método consiste em o pesquisador ouvir e registrar, após questão desencadeadora o que o entrevistado tem a dizer sobre o tema; o terceiro, do observando, desenvolve-se a partir da observação pelo pesquisador do comportamento das pessoas frente ao fenômeno ou fato estudado.

Deste modo, utilizou-se como método para trabalho de campo o "perguntando", construindo-se os questionários de entrevistas dos Anexos 01 e 02 , que foram aplicados junto aos produtores rurais e pesquisadores da horticultura ornamental em diversas universidades sul-rio-grandenses, que serão explicados a seguir:

\section{a) Das entrevistas realizadas junto aos pesquisadores.}

As perguntas desencadeadoras do questionário de pesquisa aos técnicos estão agrupadas em quatro partes, conforme o tipo de respostas. Com a aplicação do primeiro grupo de questões do formulário de entrevistas (Anexo 01), tais como a idade, sexo e tempo de residência no local, dentre outras, conforme já afirmou Tuan (1983), pretendeu-se buscar as interferências no processo percepto-cognitivo ambiental do entrevistado a respeito da produção de roseiras no Estado.

Com a aplicação do segundo grupo de perguntas desencadeadoras, pretendeu-se fazer uma breve análise da vida profissional do técnico, 
a fim de evidenciar sua experiência no assunto, perguntando-se, por exemplo, há quantos anos se dedica à pesquisa sobre rosas e como, ou com quem começou a pesquisar sobre o assunto.

O terceiro grupo de questões desencadeadoras visou obter-se uma análise sobre a planta propriamente dita, no caso, a roseira, investigando-se, do ponto de vista do conhecimento técnico, a melhor época para seu plantio e colheita, as fases fenológicas, bem como sobre o mercado consumidor do Rio Grande do Sul.

O último grupo de questões refere-se ao clima do Estado, na qual o entrevistado foi questionado sobre seus conhecimentos relacionados às exigências meteorológicas das roseiras em suas fases fenológicas, bem como suas considerações e avaliações sobre o clima do Estado em relação a ser favorável ou não para a produção de roseiras ao ar livre.

\section{b) Das entrevistas realizadas junto aos agricultores.}

O outro Questionário de Investigação, que foi aplicado junto aos agricultores, assim como o questionário dos técnicos, também foi agrupado em quatro partes, conforme o tipo de respostas (Anexo 02). No primeiro grupo de questões, foram levantadas informações como a idade, sexo e tempo de residência no local, dentre outras, baseando-se também nas afirmações de Tuan (op. cit.).

O segundo grupo de perguntas desencadeadoras pretendeu-se fazer uma breve análise da vida agrícola do produtor rural, bem como de sua propriedade, perguntando-se, por exemplo, há quantos anos se dedica ao plantio de rosas, como, ou com quem, começou a plantar, além do tamanho da propriedade, quais as variedades de rosas que são produzidas e se havia o conhecimento de onde e quem erma os compradores.

Já o terceiro grupo de questões desencadeadoras visou obter uma análise sobre o conhecimento do agricultor sobre a roseira propriamente dita, investigando-se, qual a melhor época para seu plantio e colheita segundo seu juízo de valor e experiência como produtor rural, conhecimento sobre suas fases fenológicas, o que foi perguntado com um vocabulário coloquial a fim de que o agricultor entendesse o que lhe era perguntado.

O Quarto e último grupo de questões referem-se ao clima do Estado, na qual o agricultor foi questionado sobre seus conhecimentos empíricos relacionados às exigências bioclimáticas das roseiras, bem como seu julgamento sobre a (des) favorabilidade do clima do Estado para a produção de roseiras ao ar livre. Além disso, foram realizadas perguntas como se já haviam tido prejuízos em seu roseiral em função de temporais, geadas, secas, dentre outras causas de origem climática, podendo indicar fenômenos climáticos que só podem ser investigados em análise diária.

\section{RESULTADOS E DISCUSSÕES}

Foram realizadas, como procedimentos metodológicos, atividades de campo nas quais o principal objetivo foi coletar informações sobre a cultura da roseira, tanto de pesquisadores das principais Universidades do Rio Grande do Sul, quanto de agricultores, que pudessem exprimir sua experiência no campo, para reforçar a revisão bibliográfica e auxiliar a na interpretação dos resultados.

Tais atividades foram realizadas entre os dias 15 e 22 de maio de 2009, percorrendo nove municípios do Estado do Rio Grande do Sul (Porto Alegre, São Sebastião do Caí, Antônio Prado, Santa Maria, Uruguaiana, Santo Ângelo, Passo Fundo, Gramado e Osório), compreendendo as principais regiões produtoras de roseiras do Estado, consistindo na aplicação dos questionários desencadeadores da pesquisa (Anexos 01 e 02) diferenciados para os Técnicos e para os Agricultores, respectivamente. As atividades e viagens realizadas neste período estão melhores descritas a seguir.

O mapa da Figura 02 mostra as regiões produtoras de roseiras e as cidades inclusas no roteiro de atividades referentes ao trabalho de campo nas regiões produtoras.

\section{a) Da Análise das Entrevistas aos Técnicos}

Para a análise das entrevistas realizadas com os técnicos através da aplicação do questionário do Anexo 01, optou-se pela separação das análises, ou seja, serão analisadas separadamente as respostas de cada um dos três técnicos entrevistados, para evitar possíveis dúvidas aos leitores.

Para o Técnico 01, Engenheiro Agrônomo, dedica-se à pesquisa em floricultura há 16 anos, quando perguntado sobre como começou a pesquisar sobre as rosas, o Agrônomo colocou que sua iniciação à pesquisa nesta área deu-se no Mestrado, analisando enxertos em determinada espécie.

Inicialmente, foram-lhe perguntadas questões referentes à análise sobre a planta. Em relação ao cultivo de rosas, o técnico considera que a maior produção dá-se ao ar livre no Rio Grande 


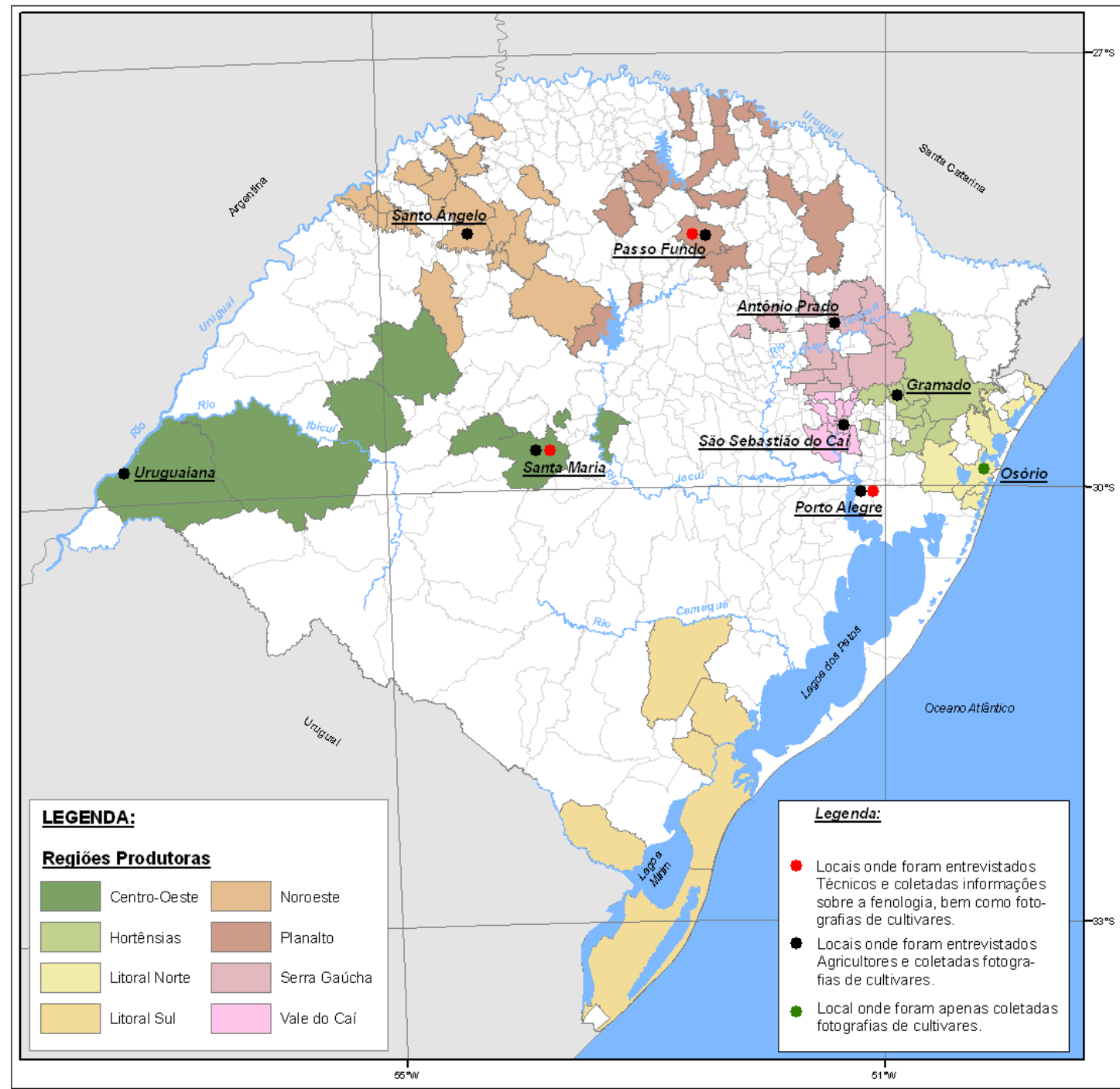

Figura 02 - Regiões produtoras e cidades inclusas no roteiro de atividades referentes ao trabalho de campo entre os dias 15 e 22 de maio de 2009. Fonte: WOLLMANN, C. A., 2012.

do Sul, salientando que o Estado apresenta muitos ambientes climáticos, como a Serra, Rebordo e o próprio Planalto, Campanha, entre outros e que apresentam as quatro estações bem definidas. Ainda, o pesquisador citou que a rosa possui uma série de variedades e um mundo de gêneros que podem afetar profundamente na adaptação da planta a este ou aquele tipo de clima. Dependendo do cruzamento obtido, a nova espécie adapta-se melhor ao cultivo protegido ou ao cultivo a céu aberto.

Quanto à posição do mercado produtor/ consumidor do Rio Grande do Sul frente ao mercado nacional e internacional, o técnico 01 colocou que a produção gaúcha é pequena frente a outros pólos de produção consagrados no Brasil, como os de São Paulo, Minas Gerais e Ceará. Ainda, o consumo sul-rio-grandense é maior que a produção. Ao final, o pesquisador coloca que tem percebido que o clima parece ser o grande limitador para fortalecer a produção de rosas no Rio Grande do Sul e competir com outras regiões. Tal resposta vem ao encontro da hipótese desta pesquisa.

Quando questionado sobre a situação do produtor em relação aos planos de fomento à produção, é citado que o fomento à floricultora no Rio Grande do Sul é pequeno, pois o custo tecnológico, logístico e estrutural é alto, mesmo existindo o mito de que a atividade é muito rentável. O engenheiro salienta que para se produzir rosas é necessário muito conhecimento para se alcançar qualidade.

Ainda, o mesmo diferencia dois tipos de produtores. Para ele, existe o "produtor empresário", que está pautado na tecnologia, e o "produtor de tradição familiar", que baseia seus conhecimentos e técnicas obtidas ao longo das gerações que produziram a rosa. Ainda, salienta que ambos os perfis de produtores parecem persistentes na atividade, pois parece que das flores, a rosa "é a única que não sai 
de moda" [palavras do entrevistado].

Quando questionado sobre qual a melhor época para poda, é salientado que depende de subclasse de rosa, logo, pode ser toda estação do ano ou apenas uma delas, pois depende da variedade. No que se refere ao plantio, é colocado que a primavera e o outono são as melhores épocas para a realização de tal atividade. Para a colheita, as melhores épocas citadas foram a primavera e o outono.

Sobre as fases fenológicas da roseira, o técnico afirma que o ciclo vegetativo da roseira depende muito da temperatura. A planta, no frio sul-rio-grandense, pode produzir uma flor num prazo de 60 dias, enquanto que no calor, esse tempo diminui para 45 dias. Ainda, coloca que a fase vegetativa corresponde a $2 / 3$ do ciclo, enquanto que o restante seria ocupado pela fase reprodutiva.

Ao ser questionado sobre quantas colheitas podem ser realizadas durante um ano, o técnico coloca que podem ser realizadas até cinco colheitas no cenário Sul-Rio-grandense, pois depende muito dos sistemas de produção, e principalmente, das condições climáticas.

No segundo grupo de questões, que se referem à análise do clima ideal para o cultivo da roseira, bem como da análise do clima do Rio Grande do $\mathrm{Sul}$, ao ser questionado sobre quais as condições climáticas adequadas para o pleno desenvolvimento da roseira em cada uma de suas fases fenológicas, $o$ agrônomo colocou que a alta intensidade luminosa, acima de $100 \mathrm{klx}$ (kLux), temperaturas entorno de $22^{\circ} \mathrm{C}$ durante o dia e $18^{\circ} \mathrm{C}$ durante a noite, e umidade relativa do ar entre $70-80 \%$ são ideais em todas as fases fenológicas da roseira.

$\mathrm{Na}$ questão relativa a que forma pela qual a temperatura, as chuvas, os ventos, as geadas, dentre outros atributos climáticos podem interferir de forma positiva e negativa na cultura da roseira, foi colocado que a fisiologia da planta é completamente e facilmente atingida pelas variações meteorológicas. O técnico salientou que a temperatura define o comprimento do ciclo, tamanho do botão, comprimento da haste e o estresse da planta; as chuvas e ventos definem a umidade do solo e do ar, que repercutem no fluxo de água na planta, processos que são importantes para a nutrição e transpiração da planta, bem como para a dispersão de doenças. Por fim, a geada foi destacada pelo técnico como o fator que pode parar o crescimento e desenvolvimento da planta, podendo causar queimaduras e congelamento dos tecidos.

Em relação aos principais prejuízos ocorridos em roseirais por causas climáticas, foi colocado que os prejuízos maiores sempre são nas infraestruturas, como as estufas, especialmente quando ocorrem temporais de verão. Ainda, salienta que há a perda de safras inteiras devido à queda de granizo e grandes estiagens.

Ao ser perguntado sobre a favorabilidade do clima do Vale do Caí e Grande Porto Alegre para a produção de rosas, o técnico colocou que não é o ideal, pois há pouca luz no inverno. No entanto, no verão é muito quente, mas no inverno não é tão frio como em outras regiões do Rio Grande do Sul. Salientam que o diferencial da produção na região dá-se em função da proximidade com os maiores pólos consumidores de rosa no Estado, como a Região Metropolitana de Porto Alegre.

Nas questões de qualificação dos atributos climáticos da região questionada para o cultivo da roseira, o técnico coloca que a temperatura média do ar ideal para o cultivo de roseiras está em torno de $20^{\circ} \mathrm{C}$; as chuvas precisam ser regulares, mas sem excesso, pois do contrário, ocorre diminuição da luz em função do aumento na nebulosidade; em relação aos ventos, é colocado que deve ser uma ventilação amena, para boa circulação de ar para evitar a condição de umidade favorável à formação de fungos; umidade relativa do ar em torno de $70 \%$; Sol pleno e sem ocorrência de geadas formariam uma situação climática favorável ao desenvolvimento pleno da roseira.

Em relação à conceituação dos elementos do clima do Rio Grande do Sul para a produção de rosas, as temperaturas médias, chuvas, umidade relativa e Sol são bons, enquanto que os ventos e a geada são regulares para o pleno desenvolvimento dos roseirais.

O Técnico 02, também Engenheiro Agrônomo, que se dedica à pesquisa de rosas há pelo menos 30 anos e seu interesse veio da produção familiar, bem como de uma prima que também é pesquisadora desta área.

Inicialmente, foram-lhe perguntadas questões referentes à análise sobre a planta. Em relação ao cultivo a céu aberto, $\mathrm{O}$ técnico 02 colocou que sem estufas não como produzir rosas no Rio Grande do Sul, principalmente em função das grandes variações climáticas ligadas ao fenômeno E1 Niño.

Em relação à posição do mercado produtor/ consumidor sul-rio-grandense, o engenheiro colocou que o Estado é o maior consumidor nacional, mas salientou que as rosas de melhor qualidade comercializadas no Rio Grande do Sul sempre são importadas de outros estados brasileiros. Quanto aos programas de fomento à floricultura, a formação de cooperativas de produtores rurais (floricultores) e o apoio do SEBRAE têm sido os principais apoios encontrados para quem se dedica á produção de flores e plantas ornamentais, como a rosa. 
Ao ser questionado sobre qual a melhor época para a poda, o técnico colocou que pode ser realizada em qualquer época do ano, mas que no inverno realiza-se a poda baixa, pois a planta precisa hibernar. Ainda, o pesquisador indica o inverno para o plantio de mudas com raízes nuas. Sobre o tempo que uma planta leva para atingir seu desenvolvimento pleno, caso semeado, conforme citado, de um ano a um ano e meio tem-se uma planta adulta.

A melhor época citada para a colheita foi a primavera. Sobre quantas colheitas podem ser realizadas em um ano, $\mathrm{O}$ técnico 02 salienta que depende da época, pois a temperatura é o principal fator que determina o tamanho do ciclo de crescimento. Em condições de verão, a cada 35-45 dias é possível realizar uma colheita, enquanto que em condições invernais, caso não seja feita a poda baixa, esse período cresce para 60-70 dias.

O segundo grupo de questões está relacionado à análise o clima ideal para o cultivo da roseira, bem como da favorabilidade do clima do Rio Grande do Sul para o cultivo desta flor. Quando perguntado quais seriam as condições climáticas adequadas para o pleno desenvolvimento da roseira em cada uma de suas fases fenológicas, o Professor citou a temperatura média do ar como o principal fator limitante, destacando que temperaturas médias constantes entre $12^{\circ} \mathrm{C}$ e $18^{\circ} \mathrm{C}$ são as mais favoráveis. Ainda, destacou que utilização de estufas no verão piora este quadro, pois deixa a temperatura do ar mais elevada.

Ao ser questionado sobre a forma na qual a temperatura, as chuvas, os ventos, as geadas, dentre outros atributos climáticos podem interferir de forma positiva e negativa na cultura da roseira, $\mathrm{O}$ técnico 02 salientou que as temperaturas devem ser amenas, especialmente na brotação. A ocorrência de dias nublados e abafados é prejudicial, pois além das temperaturas serem elevadas, a iluminação é baixa.

$\mathrm{O}$ autor citou o Vento Norte como grande destruidor dos roseirais na região de Santa Maria. Este vento é historicamente citado e foi muito estudado por Sartori (2000; 2003c), abordando que:

"É conhecido e mencionado desde o início da ocupação do território sul-rio-grandense e identificado pelos primeiros viajantes europeus que fizeram excursões de reconhecimento da terra do Brasil colonial, especialmente durante o século XIX, como Arsène Isabelle e Augusto de Saint-Hilaire, que narraram detalhes minuciosos do ambiente ao longo dos seus trajetos. Entre os dias 25 de fevereiro e $1^{\circ}$ de março de 1834, Isabelle (1949) descreve a região de Santa Maria em que se encontrava, chamando atenção para as condições atmosféricas e relevo, identificando-se a situação pré-frontal que enfrentaram, com o forte vento norte, de poucas horas de duração, e temperaturas muito altas. Porém, foi Machado (1950) que apresenta as primeiras explicações à origem do Vento Norte regional, chamando atenção para a particular violência que ele assumia em Santa Maria. Com Sartori $(1979,1981,1984,2000)$, é que foram buscadas maiores explicações sobre a origem do Vento Norte regional e, mais especificamente, sobre as causas do Vento Norte em Santa Maria". (SARTORI, 2003, p. 1).

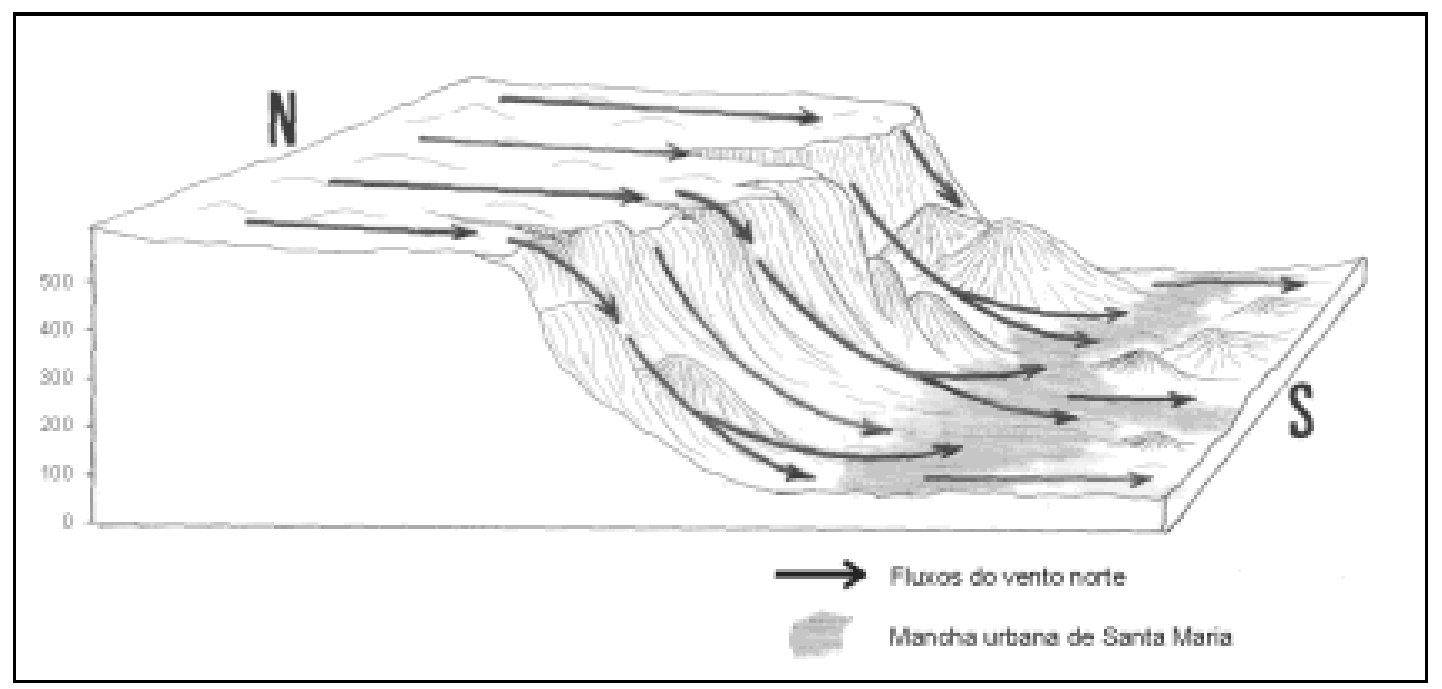

Figura 03 - O Vento Norte regional, as alterações de fluxo por influência do relevo. Fonte: Trabalho de Campo, 2009. Org.: WOLLMANN, C. A., 2012. 
Sua gênese está ligada à dinâmica atmosférica regional, especialmente em relação às situações pré-frontais no Rio Grande do Sul, quando a massa de origem polar atlântica, em geral aquecida basalmente, tornando-se massa de origem polar velha (Sartori, 1979), promovendo fluxos de Norte que atingem o Estado e destaca-se em Santa Maria com relativa violência, conforme salientado pela autora. Tal "violência" é em função de alguns condicionantes geoambientais locais, representados pelo relevo e pela presença da cidade, que podem se melhor visualizados na Figura 03.

Em relação aos principais prejuízos ocorridos em roseirais por causas climáticas, $\mathrm{O}$ técnico 02 coloca que os prejuízos maiores estão relacionados às temperaturas extremamente baixas, pois abaixo de $10^{\circ} \mathrm{C}$, salienta o pesquisador, a roseira não cresce. Ao ser perguntado sobre a favorabilidade do clima da Região de Santa Maria para a produção de roseiras, o agrônomo citou que não é a ideal, pois o Vento Norte é muito prejudicial aos cultivares, especialmente porque derruba as estufas das produções cobertas; a temperatura oscila muito, sendo comum a ocorrência de ondas de frio e de calor no inverno e verão, respectivamente, o que é muito prejudicial à roseira, mas salientou que as chuvas são bem distribuídas ao longo do ano, condição favorável para o desenvolvimento do cultivar.

Nas duas últimas questões de qualificação dos atributos climáticos da região de Santa Maria para o cultivo da roseira, o Professor O técnico 02 colocou que as temperaturas ideais estão na faixa de $12^{\circ} \mathrm{C}$ a $24^{\circ} \mathrm{C}$, enquanto que a faixa marginal de cultivo estaria entorno de $24^{\circ} \mathrm{C}$ a $27^{\circ} \mathrm{C}$, ainda, informa que temperaturas superiores a $37^{\circ} \mathrm{C}$ ocorre a paralisação do crescimento das folhas; chuvas bem distribuídas no Rio Grande do Sul são ideais; sobre os ventos, todos são favoráveis, à exceção do Vento Norte, que é destruidor; umidade relativa do ar entorno de $70 \%$; Sol abundante, pois a roseira é um planta que "gosta" de luz solar; e em relação à geadas, o pesquisador colocou que a roseira é bem resistente à este fenômeno, mas temperaturas abaixo de $0^{\circ} \mathrm{C}$ podem matar brotos novos, comprometendo todo o desenvolvimento de uma planta e até mesmo de um roseiral.

Por fim, para a conceituação dos elementos do clima do Rio Grande do Sul para a produção de rosas, $\mathrm{O}$ técnico 02 classificou os ventos e umidade relativa do ar como péssimos; temperatura média do ar como regular; e chuvas, Sol e geada como bons.

O terceiro e último pesquisador entrevistado (técnico 03), ligado ao curso de Agronomia da Universidade de Passo Fundo, dedica-se ao estudo e pesquisa das flores e plantas ornamentais há pelo menos 15 anos, iniciando seus estudos em função da necessidade de pesquisadores na área, bem como exercício do ensino.

O primeiro grupo de perguntas desencadeadoras, que dizem respeito à análise sobre a roseira propriamente dita, $\mathrm{O}$ técnico 03 salienta que a maior parte do cultivo de rosas no Rio Grande do Sul dá-se ao ar livre. Assim, como exposto pelo técnico 02, o técnico 03 também coloca que o Rio Grande do Sul é o maior consumidor nacional, mas salientou que maioria das rosas comercializadas no Estado são importadas de outros estados brasileiros.

Quanto aos programas de fomento à floricultura, a formação de cooperativas e associações de floricultores, o apoio do SEBRAE e do Programa Nacional de Apoio à Agricultura Familiar (PRONAF) são os principais apoios encontrados para quem se dedica á produção de roseiras, conforme esclarece a pesquisadora.

Quando questionado sobre qual a melhor época para a realização da poda, o técnico 03 salientou que os meses outonais e invernais são os melhores para a realização da poda baixa, e que a melhor época para o plantio seria o inverno, quando plantada sob a forma de raiz nua. Ainda, em relação ao tempo gasto, em média, para a planta atingir seu desenvolvimento pleno em todas as fases, a pesquisadora salienta que, através do método reprodutivo com uso de enxerto, o broto surge após cerca de 45 dias; No entanto com a semeadura leva pouco mais de um ano.

Em relação à melhor época para a colheita, O técnico 03 coloca que todas as estações são ideais, e que a cada 45 dias pode ser realizada uma nova colheita. Entretanto, a entrevistada chama atenção para as colheitas de inverno, que são podas baixas, necessárias, pois a planta necessita entrar em dormência.

O segundo e último grupo de questões está relacionado à análise o clima ideal para o cultivo da roseira, bem como da favorabilidade do clima do Rio Grande do Sul para o cultivo desta flor. Quando perguntado quais seriam as condições climáticas adequadas para o pleno desenvolvimento da roseira em cada uma de suas fases fenológicas, a agrônoma salientou que o frio é essencial para o período de dormência da planta, entretanto, nos demais meses é interessante que a temperatura média se mantenha constante, sem muitas variações.

Em relação às formas como a temperatura, as chuvas, os ventos, as geadas, dentre outros atributos climáticos podem interferir de forma positiva e negativa na cultura da roseira, $\mathrm{O}$ técnico 03 salientou que alta umidade relativa do ar é muito favorável para o surgimento de doenças nas roseiras; 
além disso, chuvas constantes, mas não fortes, são essenciais para o desenvolvimento pleno do roseiral; e temperaturas muito elevadas são prejudiciais à formação da pétala.

Dentre os principais prejuízos registrados em roseiras cujas causas estejam ligadas às de origem climática na região de pesquisa, a pesquisadora salienta que os maiores estragos sempre ocorrem devido à chuva de granizo. Sobre a favorabilidade do clima da Região de Passo Fundo para a produção de roseiras, a engenheira disse ser um clima muito favorável para a roseira, pois apresenta ar fresco, um inverno rigoroso, mas os roseirais são podados, e o verão é mais ameno, bem como os valores de umidade relativa do ar são menores.

Na penúltima questão de qualificação dos atributos climáticos da região de Passo Fundo para o cultivo da roseira, o técnico 03 salienta que as temperaturas diurnas devem permanecer entre $23^{\circ} \mathrm{C}$ e $25^{\circ} \mathrm{C}$ e as noturnas entre $12^{\circ} \mathrm{C}$ e $15^{\circ} \mathrm{C}$. O técnico 03 ainda destaca que a roseira não é sensível ao fotoperíodo.

Na última questão referente à qualificação dos elementos do clima na região de pesquisa, para os ventos e a geada, o técnico 03 os classificou como regulares; a temperatura ótima; e chuvas, umidade relativa e Sol como muito bons para o cultivo de roseiras.

\section{b) Da Análise das Entrevistas aos Agricultores}

Foram entrevistados durante os dias 15 e 23 de maio de 2009, oito produtores de rosas em sete diferentes municípios, sendo 7 do sexo masculino e 1 do sexo feminino. Todos os entrevistados moravam no local entrevistado há pelo menos 20 anos, mas nem todo esse tempo foi gasto produzindo rosas. Dos oito entrevistados, dois deles possuíam floricultura, na qual vendiam sua produção de rosas.

Para melhor compreender os resultados encontrados após aplicação do questionário do Anexo 10, a pesquisa foi dividida em três partes, de acordo com o grupo de questões desencadeadoras do instrumento de pesquisa. O primeiro grupo de questões está relacionado à análise sobre o produtor; o segundo grupo de perguntas diz respeito à análise da planta (roseira), e o terceiro e último grupo de questões desencadeadoras relacionaram-se à favorabilidade do clima de sua região para a cultura da roseira.

\section{DAS QUESTÕES SOBRE O PRODUTOR}

A primeira questão desencadeadora colocada fazia menção à quantidade de anos dedicados à produção de rosas. Dos 8 (oito) entrevistados, 3 (três) produziam há menos de, sendo 1 (um) deles havia entrado para a rosicultura há menos de 1 ano, outro produzia há menos de 5 (cinco) anos, enquanto o outro produzia rosas entre 5 (cinco) e 10 (dez) anos; 1 deles produzia há mais de 10 anos, porém menos de 20 anos; e apenas 1 (um) entrevistado produzia rosas há mais de 20 anos.

Nesse sentido, a Tabela 01 mostra a quantidade de entrevistados, as classes de respostas coletadas e a porcentagem referente à quantidade de anos dedicados à produção de rosas. Cabe ressaltar que a maioria dos entrevistados, no entanto realiza tal atividade há pelo menos 10 anos, o que lhe conferem bom conhecimento sobre a planta e sobre o clima da área na qual realizam sua prática agrícola.

Tabela 01 - Quantidade de anos dedicados à produção de rosas.

\begin{tabular}{llr}
\hline \multicolumn{1}{c}{ Respostas coletadas } & $\mathbf{n}$ & \% \\
\hline Menos de 1 ano & 1 & 12,5 \\
\hline De 1 a 5 anos & 1 & 12,5 \\
\hline De 5 a 10 anos & 1 & 12,5 \\
\hline De 10 a 20 anos & 3 & 37,5 \\
\hline Mais de 20 anos & 2 & 25,0 \\
\hline Total & $\mathbf{8}$ & $\mathbf{1 0 0 , 0}$ \\
\hline
\end{tabular}

Fonte: Trabalho de Campo, 2009. Org.: WOLLMANN, C. A., 2012.

A segunda questão referia-se ao tamanho da propriedade utilizada para a produção de roseiras. As respostas dos entrevistados podem ser melhor visualizadas na Tabela 02 .

Tabela 02 - Tamanho da propriedade rural dos entrevistados.

\begin{tabular}{lcr}
\hline \multicolumn{1}{c}{ Respostas coletadas } & $\mathbf{n}$ & \% \\
\hline Menos de 1 hectare & 4 & 50,0 \\
\hline De 1 a 5 hectares & 3 & 37,5 \\
\hline De 5 a 10 hectares & 0 & 0,0 \\
\hline Mais de 10 hectares & 1 & 12,5 \\
\hline Total & $\mathbf{8}$ & $\mathbf{1 0 0 , 0}$ \\
\hline
\end{tabular}

Fonte: Trabalho de Campo, 2009. Org.: WOLLMANN, C. A., 2012

De acordo com a Tabela 02, observa-se o predomínio de propriedades com menos de 10 hectares que estejam ligadas à produção de rosas, somando-se $87,5 \%$ do total dos entrevistados. Esta 
situação rural reforça o relatório do IBGE (1996) sobre o diagnóstico da floricultura brasileira, ao colocar que a maioria das atividades ligadas à floricultura ocorria em propriedades do tamanho mencionado.

A terceira pergunta referente à análise do produtor sobre as variedades na coloração das rosas produzidas em sua propriedade rural. Para tal, a Tabela 03 aponta as respostas dadas pelos entrevistados.

Tabela 03 - Variedades produzidas pelos agricultores, de acordo com a coloração.

\begin{tabular}{lcr}
\hline \multicolumn{1}{c}{ Respostas coletadas } & $\mathbf{n}$ & \% \\
\hline Vermelha & 10 & $\mathbf{2 2 , 7}$ \\
\hline Amarela & 11 & 25,0 \\
\hline Branca & 6 & 13,6 \\
\hline Rosa & 8 & 18,1 \\
\hline Champanhe / Laranja & 4 & 9,1 \\
\hline Bordô & 3 & 6,8 \\
\hline Multicolor & 2 & 4,5 \\
\hline Total & $\mathbf{4 4}$ & $\mathbf{1 0 0 , 0}$ \\
\hline
\end{tabular}

Fonte: Trabalho de Campo, 2009. Org.:WOLLMANN,C. A., 2012.

Cabe ressaltar que nesta questão o agricultor poderia mencionar mais de uma resposta, uma vez que produz diferentes gêneros de rosáceas. Ao total, foram coletadas 44 respostas diferentes. Dentre as cores mais citadas, estão a amarela, a vermelha, e rosa e a branca, com $25,0 \%, 22,7 \%, 18,1 \%$ e $13,6 \%$ das respostas, respectivamente. Demais cores também foram citadas, mas possuem representatividade menos em comparação com as anteriores.

Esta resposta reforça o tipo de produto final, no que se refere à coloração das pétalas de rosas, buscado pelos consumidores, e que foi mencionado por Barbosa (2003) e Lopes (2007), ao expor que as variedades mais buscadas são as vermelhas e amarelas.

A quarta questão referia-se à produtividade média atingida nas propriedades dos entrevistados. Dos oito entrevistados, 4 deles (50\%) tinham uma produtividade média de 500 a 1000 dúzias de rosas por mês, o que equivale de 6000 a 12000 botões de rosa colhidos por mês em cada hectare produzido. Segundo Takane (2007), a média brasileira é de 18000 botões de rosa mensais por hectare. Nesse sentido, observa-se que a produção gaúcha está muito aquém da média dos maiores estados brasileiros, conforme cita o autor.

Para uma melhor visualização dos resultados, a Tabela 04 apresenta as demais respostas colhidas entre os entrevistados no que diz respeito à produtividade média atingida em suas propriedades

Tabela 04 - Produtividade média atingida (dúzias/ mês/hectare).

\begin{tabular}{lcr}
\hline $\begin{array}{c}\text { Respostas coletadas } \\
\text { (dúzias/mês/hectare) }\end{array}$ & n & \% \\
\hline Menos de 100 & 1 & 12,5 \\
\hline De 100 a 500 & 0 & 0,0 \\
\hline De 500 a 1000 & 4 & 50,0 \\
\hline Mais de 1000 & 1 & 12,5 \\
\hline Não sabe & 2 & 25,0 \\
\hline \hline Total & $\mathbf{8}$ & $\mathbf{1 0 0 , 0}$ \\
\hline
\end{tabular}

Fonte: Trabalho de Campo, 2009. Org.: WOLLMANN, C. A., 2012

A última questão a respeito da análise da produção e dos produtores está relacionada à época do ano na qual há maior procura por botões de rosa. Segundo os entrevistados, salientando que nesta questão os mesmos poderiam se referir a mais de uma data lembrada, as datas de maior procura é o Dia das Mães e Dia dos Namorados, com 28,5\% das respostas cada.

O dia das Mães e dos Namorados ocorrem, respectivamente, em maio e junho, meses outonais no Rio Grande do Sul e que antecedem à poda baixa, pois a planta entrará em dormência vegetativa; logo, estas datas são importantes para os roseiristas sul-rio-grandenses, pois fecham o calendário comercial e fenológico (de manejo) das roseiras para o Estado.

Tabela 05 - Épocas do ano de maior procura por rosas.

\begin{tabular}{lcr}
\hline \multicolumn{1}{c}{ Respostas coletadas } & $\mathbf{n}$ & $\mathbf{\%}$ \\
\hline Dia das Mães e Mês das Noivas & 6 & $\mathbf{2 8 , 5}$ \\
\hline Dia dos Namorados & 6 & $\mathbf{2 8 , 5}$ \\
\hline Dia de Finados & 2 & 9,5 \\
\hline Dia Internacional da Mulher & 3 & 14,2 \\
\hline Sem datas específicas & 2 & 9,5 \\
\hline Formaturas de final de ano & 2 & 9,5 \\
\hline Total & $\mathbf{2 1}$ & $\mathbf{1 0 0 , 0}$ \\
\hline
\end{tabular}

Fonte: Trabalho de Campo, 2009. Org.: WOLLMANN, C. A., 2012.

Ainda, foi feita referência ao dia de Finados, que ocorre na primavera (02 de novembro) e reabre o calendário comercial sul-rio-grandense após o período de dormência invernal. O Dia Internacio- 
nal da Mulher, em 08 de março, também foi citado como uma data importante do verão. Também foram citadas a grande procura em datas não especificas, bem como a grande procura em épocas de formaturas do Ensino Superior, que ocorrem, em geral, no final de ano, nas principais universidades Sul-Rio-grandenses.

A Tabela 05 mostra de forma mais detalhada a porcentagem de citações relacionadas às datas de maior procura por rosas, segundo respostas dos agricultores entrevistados, relembrando que os mesmos poderiam se referir a mais de uma data lembrada, somando-se ao final, 21 respostas.

\section{Das questões sobre a planta}

O segundo grupo de questões abordadas pelo questionário (Anexo 02) referia-se à análise da roseira propriamente dita, segundo os conhecimentos técnicos e empíricos dos entrevistados. Quando perguntados sobre qual a melhor época para o plantio, sendo que cada entrevistado poderia citar uma ou mais época do ano, $33,3 \%$ dos entrevistados citaram a primavera como a estação do ano melhor recomendada para o plantio. Em segundo lugar, com $26,6 \%$ das citações, ficou sendo a estação do ano o inverno, especialmente para o plantio de raízes nuas (estaquia). Empatados em terceiro lugar, verão e outono, com $20,0 \%$ das citações cada estação.

Tabela 06 - Tempo necessário para o desenvolvimento pleno da roseira até atingir a fase adulta (de produção comercial de flores), quando semeada.

\begin{tabular}{lcc}
\hline \multicolumn{1}{c}{ Respostas coletadas } & $\mathbf{n}$ & $\mathbf{\%}$ \\
\hline Menos de 12 meses & 1 & 12,5 \\
\hline De 12 a 15 meses & 3 & 37,5 \\
\hline Mais de 15 meses & 1 & 12,5 \\
\hline Não sabe & 3 & 37,5 \\
\hline Total & $\mathbf{8}$ & $\mathbf{1 0 0 , 0}$
\end{tabular}

Fonte: Trabalho de Campo, 2009. Org.: WOLLMANN, C. A., 2012.

A seguinte questão dizia respeito à qual a melhor estação do ano para a realização da poda. Aqui, cada entrevistado também sugeriu mais de uma estação, totalizando 13 (treze) respostas. A estação mais citada para a prática da poda foi o inverno, com 7 (sete) respostas (53,3\% do total), em função da necessidade de repouso vegetativo da roseira, bem como a desfavorabilidade das condições climáticas invernais no Rio Grande do Sul. As estações do ano posteriormente mais citadas foi o outono, com $23,0 \%$, o verão, com $15,4 \%$, e a primavera, citada apenas uma vez, totalizando $8 \%$ das respostas.

Quando questionado sobre quanto tempo necessário é gasto para o desenvolvimento pleno da roseira, quando semeada, os agricultores referiram-se, cada um, há um tempo especifico, pois segundo eles, depende muito da variedade e que se está semeando. Para melhor classificar a respostas dos entrevistados, a Tabela 06 mostra o tempo necessário para a roseira atingir a fase de produção comercial de rosas, quando semeada.

Seguidamente, foi-lhes perguntado qual a melhor época para a realização da colheita. Todos os entrevistados foram incisivos ao responder que a colheita da rosa dá-se diariamente, pois a cada dia novas rosas em seus pés atingem o tamanho e abertura ideal para serem colhida, ressaltando que a roseira não é uma cultura plantada uma única vez, e sim, pode-se colher rosa diariamente por vários anos, respeitando-se o período de dormência.

Entretanto, conforme citado pelos agricultores, as melhores épocas de colheita são a primavera e o verão, citados por $37,0 \%$ e $31,5 \%$ dos entrevistados respectivamente, mas segundo eles, são as melhores épocas de colheita do ponto de vista do conforto pessoal, uma vez que as noites são menos frias, pois as rosas são colhidas durante a madrugada e a céu aberto, logo o verão e a primavera apresentam maior favorabilidade para o agricultor trabalhar a céu aberto durante a madrugada.

Tabela 07 - Intervalo de tempo gasto por uma roseira para produzir novamente rosas e ser realizada uma nova colheita, segundo agricultores entrevistados.

\begin{tabular}{lcc}
\hline \multicolumn{1}{c}{ Respostas coletadas } & N & $\%$ \\
\hline De 1 a 25 dias & 4 & 40,0 \\
\hline De 25 a 50 dias & 2 & 20,0 \\
\hline Acima de 50 dias & 2 & 20,0 \\
\hline Não sabe & 2 & 20,0 \\
\hline Total & 10 & 100,0 \\
\hline
\end{tabular}

Fonte: Trabalho de Campo, 2009. Org.: WOLLMANN, C. A., 2012 .

Por fim, a última questão sobre a análise da roseira dizia respeito à qual o intervalo de tempo gasto por um pé de roseira para produzir uma rosa 
entre as colheitas. Segundo os entrevistados, esse tempo depende muito da variedade e do período do ano. Assim, foram citados mais de um período por cada roseirista, e que podem ser melhor vistos na computação da Tabela 07.

\section{Das questões sobre o clima do Rio Grande do Sul}

O terceiro e último grupo de questões está relacionado à análise o clima ideal para o cultivo da roseira, bem como da favorabilidade do clima do Rio Grande do Sul para o cultivo desta flor. Quando perguntados quais seriam as condições climáticas adequadas para o pleno desenvolvimento da roseira em cada uma de suas fases fenológicas, o que lhes foi perguntado de forma mais coloquial (de que forma os elementos do clima podem interferir de forma positiva e negativa na cultura da roseira?), os entrevistados sugeriram apenas situações climáticas negativas que podem ser atribuídas ao cultivo da roseira, e que podem ser melhor visualizadas através da Tabela 08.

A maioria dos entrevistados, $20 \%$ deles, citou as altas temperaturas, próximas dos $40^{\circ} \mathrm{C}$, como situações climáticas desfavoráveis para o cultivo de roseiras. Em segundo lugar, empatados com $15 \%$ das citações, estão: temperaturas muito baixas, próximas de $0^{\circ} \mathrm{C}$, a grande variação da temperatura (amplitude térmica), as geadas e o granizo e as rajadas de vento.

Tabela 08 - De que forma os elementos do clima podem interferir de forma positiva e negativa na cultura da roseira?

\begin{tabular}{llr}
\hline \multicolumn{1}{c}{ Respostas coletadas } & $\mathbf{n}$ & \% \\
\hline $\begin{array}{l}\text { Temperatura muito alta, } \\
\text { próxima de } 40^{\circ} \mathrm{C}\end{array}$ & 4 & 20,0 \\
\hline $\begin{array}{l}\text { Temperatura muito baixa, } \\
\text { próxima de } 0^{\circ} \mathrm{C}\end{array}$ & 3 & 15,0 \\
\hline Grande variação da temperatura & 3 & 15,0 \\
\hline Elevada umidade relativa do ar & 1 & 5,0 \\
\hline Geadas e granizo & 3 & 15,0 \\
\hline Baixa insolação / pouco Sol & 2 & 10,0 \\
\hline Ventos muito fortes / rajadas & 3 & 15,0 \\
\hline Excesso de chuvas / doenças & 1 & 5,0 \\
\hline Total & $\mathbf{2 0}$ & $\mathbf{1 0 0 , 0}$ \\
\hline
\end{tabular}

Fonte: Trabalho de Campo, 2009. Org.: WOLLMANN, C. A., 2012.
Segundo Machado (1950), Sartori (2000) e Rossato, et. al. (2004), que estudaram as ondas de calor no Rio Grande do Sul, os autores colocam que a variabilidade das temperaturas ficam acima dos valores normais, ou seja, são registradas a ocorrência de episódios em que as temperaturas diárias máximas e mínimas foram superiores a $33^{\circ} \mathrm{C}$ e $22^{\circ} \mathrm{C}$, respectivamente, por pelo menos 3 dias consecutivos e que podem desencadear inúmeros problemas para o ser humano, inclusive às repercussões negativas na agricultura.

Ainda, conforme Machado (op. cit.), ondas de calor podem ser mais frequentes na região central do Estado e são mais comuns no verão, porém, podem ocorrer em qualquer época do ano. Sartori (2000, p. 208) foi além e estabeleceu as causas dinâmicas do ponto de vista da circulação atmosférica regional para a gênese das ondas de calor na região central, bem como em todo o Rio Grande do Sul. Para a autora, as seguintes situações climáticas decorrem do "... domínio persistente, por ordem de importância, da Massa Polar Velha (MPV), da Tropical Atlântica continentalizada (MTAc) ou da Massa Tropical continental (MTc)".

No entanto, as ondas de frio, segundo Machado (op. cit. 1950), podem ser definidas como um fenômeno meteorológico que consiste em uma forte queda de temperatura dentro de certo período, assim os valores extremos necessitam satisfazer determinadas condições, ou seja, dentro de um período de tempo de 24 horas as temperaturas devem diminuir próximas a $0^{\circ} \mathrm{C}$ nas regiões de maior altitude e a $3^{\circ} \mathrm{C}$ nas regiões de menores altitudes, como na Depressão Central do Estado.

Para Sartori (2003), as ondas de frio representam períodos de duração variável (de 3 a 9 dias) com fortes quedas de temperatura, embora na maioria dos casos não ultrapasse 4 dias. Comumente, ocorrem de fins de outono até início de primavera, com maior freqüência em julho, quando se intensificam os gradientes térmicos entre as altas e baixas latitudes, estimulando as invasões dos anticiclones polares (Anticiclone Polar Atlântico).

Costa, et al. (2007), que estudou recentemente tais fenômenos, a maior freqüência desses fenômenos se deu nos meses de inverno, devido a maior participação e domínio dos sistemas atmosféricos de origem polar mais intenso, principalmente a Massa Polar Atlântica com trajetória continental pelo reforço de ar frio recebido do Anticiclone Polar Pacífico.

Ainda, dentre as condições climáticas citadas pelo agricultor, o granizo caracteriza-se, de acordo com Conti (1998), como um fenômeno climático esporádico que acontece em condições de forte 
instabilidade atmosférica, a partir da formação de nuvens cumulonimbos com grande concentração de cristais de gelo, devido aos bruscos e intensos movimentos convectivos. É um fenômeno de escala local que causa danos a todo o tipo de cultura, principalmente nas fases iniciais das etapas de crescimento das plantas.

Tabela 09 - Fenômeno climático ligado ao prejuízo no roseiral, segundo os entrevistados.

\begin{tabular}{llr}
\hline \multicolumn{1}{c}{ Respostas coletadas } & $\mathbf{n}$ & $\mathbf{\%}$ \\
\hline $\begin{array}{l}\text { Perda total por geada tardia ou } \\
\text { precoce }\end{array}$ & 2 & 25,0 \\
\hline Perda por causa da força dos ventos & 1 & 12,5 \\
\hline Queima dos botões por geada & 1 & 12,5 \\
\hline Não lembra & 4 & 50,0 \\
\hline Total & $\mathbf{8}$ & $\mathbf{1 0 0 , 0}$ \\
\hline
\end{tabular}

Fonte: Trabalho de Campo, 2009. Org.: WOLLMANN, C. A., 2012.

Muito pouco se estudou sobre a ocorrência de granizo no Rio Grande do Sul, pois no que se referem ao clima do Estado, os trabalhos de Araújo (1930), Machado (1950) e Moreno (1961), que são considerados clássicos, não abordam esse fenômeno. Merece destaque o trabalho de Berlato et al. (2000), que calcularam as probabilidades de ocorrência sazonal de granizo no Rio Grande do Sul através de técnicas estatísticas.

Recentemente, Vieira, et al. (2004), estudou os impactos da queda de granizo nas lavouras de fumo da região central do Rio Grande do Sul. Para o autor:

"Na agricultura, o granizo promove significativos estragos. A sua ocorrência é sinônimo de perda para os agricultores, pois basta uma pequena precipitação para que as perdas na lavoura sejam significativas, gerando perdas econômicas para o agricultor, indústria e município e com isso, prejuízo para toda sociedade que se relaciona direta ou indiretamente com a agricultura". (VIEIRA, et al., 2004, p. 8).

A seguinte questão foi-lhes perguntada se, no entanto, haviam sofrido algum tipo de prejuízo no seu roseiral em decorrência de fenômenos climáticos. $75 \%$ dos entrevistados afirmaram, deste modo, terem tido perda, quase ou total, de seu roseiral por conta das adversidades climáticas. Apenas dois deles (25\%) não tiveram perdas por questões climáticas. Em relação ao tipo de fenômeno climático que levou à perda do roseiral, fora os que não lembravam, pois diziam ter ocorrido há vários anos, as geadas, tardias ou precoces, foram as respostas mais enfatizadas pelos agricultores. Dos seis entrevistados que responderam afirmativamente, alguns citaram outras causas, que podem ser melhor visualizadas na Tabela 09.

Por fim, a última pergunta relacionava-se à conceituação pessoal que cada um dos agricultores achava sobre os principais atributos climáticos que tinham efeito sobre a produção de rosas. Essa questão nos induz a entender como o agricultor analisa empiricamente o clima do Rio Grande do

Tabela 10 - Considerações sobre os elementos do clima e sua influência no cultivo de roseiras, segundo os roseiricultores.

\begin{tabular}{lcccccc}
\hline \multicolumn{1}{r}{ Respostas } & Péssima & $\underline{\text { Reg. }}$ & $\underline{\text { Boa }}$ & $\underline{\text { MB }}$ & Ótima & Tot. \\
\hline Temperatura & 1 & 5 & 2 & - & - & 7 \\
\hline Chuvas & - & 3 & 3 & - & - & 6 \\
\hline Ventos & 1 & 3 & 2 & - & - & 5 \\
\hline Umidade & 1 & 4 & 2 & - & - & 7 \\
\hline Sol & 1 & 2 & 4 & 1 & - & 8 \\
\hline Geada / Neve & 2 & 3 & 3 & - & - & 8 \\
\hline Total & $\mathbf{6}$ & $\mathbf{2 0}$ & $\mathbf{1 6}$ & $\mathbf{1}$ & - & $\mathbf{4 3}$ \\
\hline Total (\%) & $\mathbf{1 3 , 9}$ & $\mathbf{4 6 , 5}$ & $\mathbf{3 7 , 2}$ & $\mathbf{2 , 4}$ & - & $\mathbf{1 0 0}$ \\
\hline
\end{tabular}

Fonte: Trabalho de Campo, 2009. Org.: WOLLMANN, C. A., 2012.

MB - Muito Boa. Reg. - Regular 
Sul e, em especial, de sua região de produção com a finalidade voltada à produção de rosas.

Não se pretendeu buscar a percepção do ponto de vista de como o agricultor sabe se determinada estação será boa ou não para a produção (previsão climática), mas apenas analisar como ele conceitua o clima do Estado na sua visão pessoal, uma vez que há a grande interelação do agricultor com a terra, sua produção e clima (SARTORI, 2002).

Nesse sentido, a Tabela 10 mostra a conceituação apresentada por cada agricultor. Aqui cada entrevistado também poderia citar mais de uma vez cada atributo climático.

De acordo com a Tabela 10, 46,5\% dos atributos climáticos citados enquadraram-se como regular para o plantio de roseiras no Rio Grande do Sul. Dentre os mais citados está a temperatura e a umidade. Ainda, 37,2\% das citações enquadraram-se em uma classificação boa, particularmente as condições de Sol.

\section{CONSIDERAÇÕES FINAIS}

Em relação aos trabalhos de campo, evidenciou-se o grande conhecimento tanto por parte dos técnicos quanto dos agricultores. O que chama a atenção é que foi perguntado aos dois grupos de entrevistados as mesmas questões, mas de forma diferente, respeitando-se seu vocabulário, obtendo-se, ao final, semelhantes respostas, tanto em relação à análise da planta quanto sobre o clima do Rio Grande do Sul.

Assim, tanto o conhecimento científico quanto o empírico servem e serviram para esta pesquisa como base para o desenvolvimento de um estudo agroclimático.

De uma forma geral, segundo a visão empírica dos agricultores, o clima do Rio Grande do Sul, bem como de sua região de produção, pode ser enquadrado entre condições regulares a boas para o cultivo da roseira.

Por fim, este estudo sobre a percepção climática voltada aos produtores e pesquisadores de roseiras ao produzidas ar livre no Rio Grande do Sul vem sanar parte as lacunas existentes nos estudos desta planta e da climatologia. Assim, esse estudo contribui não só para as indagações do autor, mas também para o rol de pesquisas da climatologia geográfica brasileira e sul-rio-grandense, servindo, portanto, como fonte teórico-metodológica que possa motivar investigações futuras.

\section{REFERÊNCIAS BIBLIOGRÁFICAS}

ARAÚJO, L. C. Memória sobre o clima do

Rio Grande do Sul. Rio de Janeiro: Serviço de Informação do Ministério da Agricultura, 1930.

BARBOSA, J. G. Produção Comercial de Rosas. Viçosa: Aprenda Fácil, 2003.

BARBOSA, J. G.; LOPES, L. C. Propagação de plantas ornamentais. Viçosa: Ed. da UFV, 2007.

BELLÉ, R. Trabalho de Campo. Universidade Federal de Santa Maria. Santa Maria - RS, 2009.

BERLATO, M. A.; FONTANA, D. C. E1 Niño E La Niña: Impactos no Clima, na Vegetação e na Agricultura do Rio Grande do Sul. Porto Alegre: UFRGS, 2002. 112 p.

CONTI, J. B. Clima e Meio Ambiente. São Paulo: Atual, 1998.

COSTA, E. R.; SARTORI, M. G. B.; FANTINI, V. et al. Estudo da relação entre eventos El Niño - La Niña e ocorrência de ondas de frio na região de Santa Maria - RS. In: SIMPÓSIO BRASILEIRO DE CLIMATOLOGIA GEOGRÁFICA, 7., 2006, Rondonópolis. Anais... Rondonópolis: UFMT, 2006. 1 CD-ROM.

INSTITUTO BRASILEIRO DE GEOGRAFIA E ESTATÍSTICA. Ministério do Planejamento, Orçamento e Gestão. Coordenação de Agropecuária.

Caracterização do setor produtivo de plantas e flores ornamentais no Brasil 1995-1996. Rio de Janeiro: IBGE, 2004. 73p.

KÄMPF, A. N. Produção comercial de plantas ornamentais. 2. ed. Guaíba: Agrolivros, 2005. 256 p.

KÄMPF, A. N.; DAUDT, R. S. Diagnóstico da floricultura no Rio Grande do Sul. Ciência e Natura, v. 29, n. 3, p. 561-563, 1999.

MACHADO, F. P. Contribuição ao estudo do clima do Rio Grande do Sul. Rio de Janeiro: Serviço Gráfico do IBGE, 1950.

MORENO, J. A. Clima do Rio Grande do Sul. Porto Alegre: Secretaria da Agricultura, 1961.

OLIVEIRA, L de; DEL RIO, V. (Org.). Percepção ambiental - a experiência brasileira. São Paulo: Studio Nobel; São Carlos: Ed. da UFSCAR, 1996. 
PETRY, C. Produção de Rosas. In.: PETRY, C. (Org.). Plantas ornamentais - aspectos para a produção. Passo Fundo: Ed. da UPF, 2000. Cap. 11, p. 113-129.

ROSSATO, P. S.; SARTORI, M. G. B.; MISSIO, L. R. et al. Gênese e frequência dos episódios de temperaturas elevadas, caracterizados como "ondas de calor", na região de Santa Maria, entre os meses de novembro a abril. In: SIMPÓSIO BRASILEIRO DE CLIMATOLOGIA GEOGRÁFICA, 6., 2004, Aracaju. Anais... Aracaju: UFS, 2004. 1 CD-ROM.

SARTORI, M. G. B. A percepção do tempo e a cognição ambiental do homem rural do Rio Grande do Sul. In: SIMPÓSIO NACIONAL SOBRE GEOGRAFIA, PERCEPÇÃO E COGNIÇÃO DO MEIO AMBIENTE, 1., 2005, Londrina. Anais... Londrina: UEL, 2005. 1 CD-ROM.

SARTORI, M. G. B. A dinâmica do clima do Rio Grande do Sul: indução empírica e conhecimento científico. Revista Terra Livre, São Paulo, v. 1, n. 20, p. 27-49, jan./jul. 2003a.

SARTORI, M. G. B.; ROSSATO, P. S.; SILVEIRA, R. D. Frequência e probabilidade de ocorrência das "Enchentes de São Miguel". In: CONGRESSO BRASILEIRO DE AGROMETEOROLOGIA, 13, 2003, Santa Maria. Anais... Santa Maria: UFSM, 2003b. 1 CD-ROM.

SARTORI, M. G. B. Gênese e características do vento norte regional em Santa Maria/RS. In: SIMPÓSIO BRASILEIRO DE GEOGRAFIA FÍSICA E APLICADA, 10., 2003, Rio de Janeiro. Anais... Rio de Janeiro: UERJ, 2003c. 1 CD-ROM.

SARTORI, M. G. B. A percepção climática no ambiente urbano e rural da região de Santa Maria - RS. In: SIMPÓSIO BRASILEIRO DE CLIMATOLOGIA GEOGRÁFICA, 5., 2002, Curitiba. Anais... Curitiba: UFPR, 2002. 1 CD-ROM.

SARTORI, M. G. B. Clima e percepção. 2000. 488p. Tese (Doutorado em Geografia) - Universidade de São Paulo, São Paulo, 2000. 2 v.

SARTORI, M. G. B. O clima de Santa Maria: do regional ao urbano. 1979. 163f. Dissertação (Mestrado em Geografia) - Universidade de São Paulo, São Paulo, 1979.
TAKANE, R. J. Cultivo de Rosas. Brasília: Editora e Comércio de Bens Editoriais e Autorais Ltda., 2007. 172 p.

TUAN, Y-F. Espaço e lugar. Tradução prefácio e notas: Lívia de Oliveira. São Paulo: DIFEL, [1983].

VIEIRA, H. R. N.; SARTORI, M. G. B.; PATUSSI, V. et al. Gênese e frequência das precipitações de granizo na região central do Rio Grande do Sul, como subsídio a prevenção de impactos na produção agrícola. In: SIMPÓSIO BRASILEIRO DE CLIMATOLOGIA GEOGRÁFICA, 6., 2004, Aracaju. Anais... Aracaju: UFS, 2004. 1 CD-ROM.

\section{WHYTE, A. V. T. La perception de}

1'environnement: lignes directrices méthodologiques pour les études sur le terrain. 7. ed. Paris: UNESCO, 1978.

WOLLMANN, C. A.; GALVANI, E. Zoneamento Agroclimático da Roseiricultura para o Estado do Rio Grande do Sul, Brasil. In.: GALVANI, E.; LIMA, N. G. B. (Orgs.). Climatologia Aplicada Resgate aos Estudos de Caso. Curitiba: Ed. CRV, 2012. Cap. 10, p. 123-136. 